\title{
Effects of Natalizumab Therapy on Intrathecal Immunoglobulin G Production Indicate Targeting of Plasmablasts
}

Miriam Schlüter, MD, Eva Oswald, BSc, Stephan Winklmeier, MSc, Ingrid Meinl, MD, Joachim Havla, MD, Peter Eichhorn, MD, Edgar Meinl, MD,* and Tania Kümpfel, MD*

Neurol Neuroimmunol Neuroinflamm 2021;8:e1030. doi:10.1212/NXI.0000000000001030

\section{Abstract}

\section{Objectives}

To evaluate the long-term effects of natalizumab (NTZ) on different features of intrathecal immunoglobulin ( $\mathrm{Ig}$ ) synthesis in patients with multiple sclerosis (MS) and to quantify the expression of a4-integrin in stages of B-cell maturation.

\section{Methods}

We combined a cross-sectional (49 NTZ-treated MS patients, mean treatment duration 5.1 years, and 47 untreated MS patients) and a longitudinal study (33 patients with MS before and during NTZ, mean treatment duration: 4.8 years), analyzing paired serum and CSF samples for $\operatorname{IgG}, \operatorname{IgA}$, and IgM levels, reactivity against selected viruses (measles virus, rubella virus, and varicella zoster virus [MRZ] reaction), and oligoclonal bands (OCBs). Banding patterns before and after therapy were directly compared by isoelectric focusing in 1 patient. In addition, we determined the expression of a4-integrin by FACS analysis on blood-derived B-cell subsets (plasmablasts, memory B cells, and naive B cells) of healthy controls.

\section{Results}

In serum, NTZ decreased IgM and IgG, but not IgA, levels. IgM hypogammaglobulinemia occurred in $28 \%$ of NTZ-treated patients. In CSF, NTZ treatment resulted in a strong reduction of intrathecally produced IgG and, to a lesser extent, IgA, whereas $\operatorname{IgM}$ indices [(Ig $\mathrm{CSF} /$ Serum $) /($ Albumin CSF/Serum)] remained largely unchanged. Reduction of the IgG index correlated with NTZ treatment duration, as did serum IgM and IgA levels. MRZ reaction was unchanged and OCB persisted. Direct comparison of OCB pattern before and after NTZ revealed the persistence of individual bands. a4-Integrin expression was highest on plasmablasts $\left(\mathrm{CD} 19^{+} \mathrm{CD} 38^{+} \mathrm{CD} 27^{+}\right)$.

\section{Conclusion}

Our data indicate that NTZ reduces short-lived plasmablasts in the CNS compartment but has little effect on locally persisting long-lived plasma cells.

\author{
Correspondence \\ Dr. Kümpfel \\ tania.kuempfel@ \\ med.uni-muenchen.de
}




\section{Glossary}

DMT = disease-modifying therapy; EID = extended interval dosing; HC = healthy control; $\mathbf{I g}=$ immunoglobulin; $\mathbf{L P}=$ lumbar puncture; MFI = mean fluorescence intensity; MRZ = measles virus, rubella virus, and varicella zoster virus; NTZ = natalizumab; $\mathbf{O C B s}=$ oligoclonal bands; PML = progressive multifocal leukoencephalopathy; RRMS = relapsing-remitting MS.

A hallmark of multiple sclerosis (MS) is intrathecal immunoglobulin (Ig) production, ${ }^{1,2}$ which has different features. First, oligoclonal bands (OCBs), mainly formed by $\operatorname{IgG} 1^{1}$; second, local IgG production against different pathogens such as measles, rubella, and varicella zoster virus (MRZ reaction $)^{3,4}$; third, a large part of the intrathecal IgG production exceeds OCB and MRZ reaction. ${ }^{5}$ Principally, there are 2 types of Igproducing cells: short-lived plasmablasts and long-lived plasma cells. ${ }^{6}$ The latter persist in survival niches, physiologically in the bone marrow, but also in the inflamed CNS. ${ }^{5,7}$ Intrathecal IgG production strongly correlates with the number of plasmablasts in the CSF. ${ }^{8,9}$

Although the bidirectional migration of B cells between blood and CNS has been elaborated, ${ }^{10}$ the role of adhesion molecules in maintenance of plasmablasts and plasma cells in the CNS is poorly understood. Natalizumab (NTZ) is a highly effective therapy for relapsing-remitting MS (RRMS) and prevents migration of immune cells into the CNS by targeting a4-integrin. NTZ has strong effects on the B-cell compartment in the periphery ${ }^{11-14}$ and in the CNS. ${ }^{15-19}$ Here, we analyzed the CSF of 49 patients with MS who were treated with NTZ for a mean of more than 5 years and underwent another lumbar puncture (LP) to exclude progressive multifocal leukoencephalopathy (PML) before switching to a different therapy. We analyzed effects of NTZ treatment on the different features of intrathecal Ig production and additionally determined a4-integrin expression on blood-derived B-cell subsets of healthy controls (HCs).

\section{Methods}

\section{Patients and Samples}

In this monocentric study, we investigated 2 groups of patients: group 1 consisted of 49 patients with RRMS treated with NTZ; group 2 consisted of 47 consecutive, age-matched, untreated patients with RRMS. Six of 49 NTZ-treated patients (12\%) received NTZ at an extended interval dosing (EID) of 6 weeks, 3 of them started EID after up to 3.5 years (mean total time of EID: 1.4 years), and 3 patients only after more than 9 years of NTZ treatment (mean total time of EID: 0.9 years); all 6 continued EID until cessation of NTZ treatment. Clinical features of all patients including disease duration, disease severity (Expanded Disability Status Scale), NTZ therapy duration, and disease-modifying treatments (DMTs) before NTZ are summarized in table 1.

All patients underwent LP for clinical and diagnostic purposes. OCB status was available for 33 patients before NTZ treatment. Immunoglobulin data from a LP before NTZ therapy were available for 27 patients with MS in the NTZtreated group. All 49 NTZ-treated patients switched therapy because of the risk of PML and underwent another LP to exclude PML before timely start of subsequent cell-depleting therapies. CSF and blood sampling at second LP was performed around the time point of patients' last NTZ application (mean time from the last NTZ infusion to lumbar puncture +11 days; range -30 to 113 days). Untreated MS patients had a diagnostic LP usually at first diagnosis. CSF and serum were analyzed by routine methods for cell count, total protein and albumin levels, OCB, IgG, IgM, and IgA. Whenever possible, residual $\mathrm{CSF} /$ serum samples were immediately centrifuged and supernatants stored at $-80^{\circ} \mathrm{C}$. None of the patients, NTZ treated or untreated, underwent plasma exchange therapy in the 30 days before LP.

\section{Cross-Sectional Study}

We compared serum and CSF IgG, IgA, and IgM levels, OCB status, and MRZ reaction of the NTZ-treated patient cohort (49 patients) with corresponding data of 47 untreated RRMS patients.

\section{Longitudinal Study}

Within the NTZ-treated cohort, we performed paired analyses of serum and CSF IgG, IgA, and IgM levels. In addition, percentage of OCB-positive patients with MS before and during NTZ therapy was determined and compared. Complete data sets before NTZ were not available for all patients of group 1; hence, patient number varied for the individual analyses (for details, see figure legends).

\section{Determination of IgG, IgA, IgM, and Albumin Levels}

The quantitative determination of immunoglobulins IgG, IgA, and IgM and albumin in serum as well as in the CSF was performed by means of immunonephelometry on an Atellica $\mathrm{NEPH} 630$ analyzer using the diagnostic reagents supplied from Siemens Healthcare Diagnostics Products GmbH, Marburg, Germany, in accordance with the manufacturer's instructions. For CSF IgM values below the quantification limit of the assay reaching from 0.12 to $0.15 \mathrm{mg} / \mathrm{L}$, these values were used for further calculations. Ig indices were calculated as

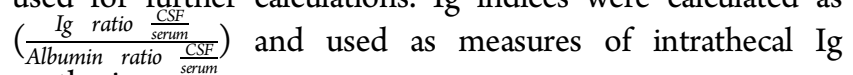
synthesis.

\section{MRZ Reaction}

MRZ reaction was detected by the calculation of the respective antibody indices (AIs) as described earlier. ${ }^{20}$ ELISAs (Euroimmun, Lübeck, Germany) were measured on an automated 
Table 1 Patient Characteristics

\begin{tabular}{|c|c|c|}
\hline & Group 1 NTZ-treated cohort & Group 2 untreated cohort \\
\hline Patient number & 49 & 47 \\
\hline Diagnosis & 49 RRMS & 47 RRMS \\
\hline Mean age at sampling (y) & 41 (range 21-65) & 39 (range 19-62) \\
\hline Sex & 30 females, 19 males (ratio 1.6:1) & 28 females, 19 males (ratio 1.5:1) \\
\hline Mean time disease onset-first lumbar puncture $(y)$ & 2 (range $0-10$ ) & 3 (range $0-22$ ) \\
\hline Mean time disease onset-first NTZ infusion (y) & 8 (range $0-21)$ & $\mathrm{n} / \mathrm{a}$ \\
\hline Mean time first lumbar puncture-first NTZ infusion (y) & 5 (range $0-14$ ) & $\mathrm{n} / \mathrm{a}$ \\
\hline Mean time disease onset-lumbar puncture during NTZ (y) & 14 (range $2-30$ ) & $\mathrm{n} / \mathrm{a}$ \\
\hline Median EDSS & 3.0 (range $0-7$ ) & 2.0 (range 1-5.5) \\
\hline Mean NTZ treatment duration $(y)$ & 5.1 (range 1.2-11.8) & $\mathrm{n} / \mathrm{a}$ \\
\hline Mean number of DMT before NTZ & 2 (range $0-7$ ) & $\mathrm{n} / \mathrm{a}$ \\
\hline Mean time from last NTZ application to lumbar puncture (wk) & $+1.5(-4.3-16.1)$ & $\mathrm{n} / \mathrm{a}$ \\
\hline
\end{tabular}

Abbreviations: DMT = disease-modifying therapy; EDSS = Expanded Disability Status Scale; NTZ = natalizumab; RRMS = relapsing-remitting MS.

ELISA processing system (Analyzer I, Euroimmun). Virusspecific $\mathrm{AI} \geq 1.5$ was considered indicative of intrathecal antibody production against the respective virus. We analyzed MRZ reaction status of untreated and NTZ-treated patients as one-fold positive (MRZ-1: reactivity against 1 of the 3 viruses) and 2-fold positive (MRZ-2: reactivity against 2 viruses) MRZ reaction.

\section{Determination of Oligoclonal Bands}

Detection of OCBs was performed as part of routine CSF analysis using a high-sensitive isoelectric focusing technique on agarose gel followed by immunofixation (Hydrasis Focusing instrument using the Hydragel 9 CSF Isofocusing kit, both Sebia, France). The presence of OCB was assumed if there was $>1$ OCB exclusively in the CSF. A sample stored at $-80^{\circ} \mathrm{C}$ in the biobank of the Institute of Clinical Neuroimmunology (LMU Klinikum, Munich) was used to analyze Ig band patterns of a patient in direct comparison before and during NTZ treatment.

\section{Flow Cytometric Analysis of a4- Integrin Expression}

We analyzed the intensity of a4-integrin expression on B-cell subsets using blood samples of HCs. Human peripheral blood mononuclear cells (PBMCs) of 8 HCs (mean age 30.5 years, male:female 5:3) were isolated using Pancoll solution (PANBiotech Pancoll human, density: $1.077 \mathrm{~g} / \mathrm{mL}$ ) and stored in liquid nitrogen until further use. After thawing, cells were incubated with the FcR blocking reagent (Miltenyi Biotec, Bergisch Gladbach, Germany) and stained using anti-human CD3Alexa Fluor 700 (OKT3; eBioscience, San Diego, CA), CD14Alexa Fluor 700 (M5E2, BioLegend, San Diego, CA), CD20PerCP (2H7 BioLegend), IgD-PerCP (IA6-2, BioLegend), CD19-APC/Fire 750 (HIB19, BioLegend), CD27-Brilliant Violet 605 (O323; BioLegend), CD38-eFluor 450 (HB7;
eBioscience), a4-integrin-(CD49d) FITC (9F10, BioLegend), and FITC Mouse IgG1, $\kappa$ Isotype Control (MOPC-21, BioLegend). B-Cell subpopulations were analyzed within the $\mathrm{CD}^{-} \mathrm{CD} 14^{-}, \mathrm{CD} 19^{+}$population. In this article, naive $\mathrm{B}$ cells were defined as $\mathrm{CD} 38^{-} \mathrm{CD} 27^{-}$; memory B cells were defined as $\mathrm{CD} 38^{-} \mathrm{CD} 27^{+}$and plasmablasts as $\mathrm{CD} 38^{+} \mathrm{CD} 27^{+}$. Expression levels of a4-integrin were analyzed as delta-mean fluorescence intensity ( $\triangle \mathrm{MFI}$ ) (MFI of VLA-4-FITC-staining - MFI of fluorescence minus one control without a4-integrin-FITC). Flow cytometry (FACS) data were analyzed using FlowJo 10.6.1 software (Ashland, OR).

\section{Statistical Analysis}

Data were analyzed using Graphpad Prism 7 software (GraphPad Software Inc., La Jolla, CA). Differences in Ig levels were evaluated using the Mann-Whitney test for crosssectional and Wilcoxon matched-pairs signed-rank tests for longitudinal comparisons. OCB and MRZ data were analyzed using the Fisher exact test. Changes in antibody levels and indices with NTZ therapy duration were evaluated using Spearman nonparametric correlation. Potential differences in a4-integrin expression levels were analyzed using the Quade all-pairs test. Differences were considered statistically significant for $p$ values of ${ }^{*} p<0.05,{ }^{* *} p<0.01,{ }^{* * *} p<0.001$, and ${ }^{* * * *} p<0.0001$ and marked accordingly in the figures.

\section{Data Availability}

After publication, anonymized data will be made available on reasonable request to the corresponding author.

\section{Standard Protocol Approvals, Registrations, and Patient Consents}

The local ethics committee (Ethik-Kommission der Medizinischen Fakultät der LMU, protocol number 159-03 and 

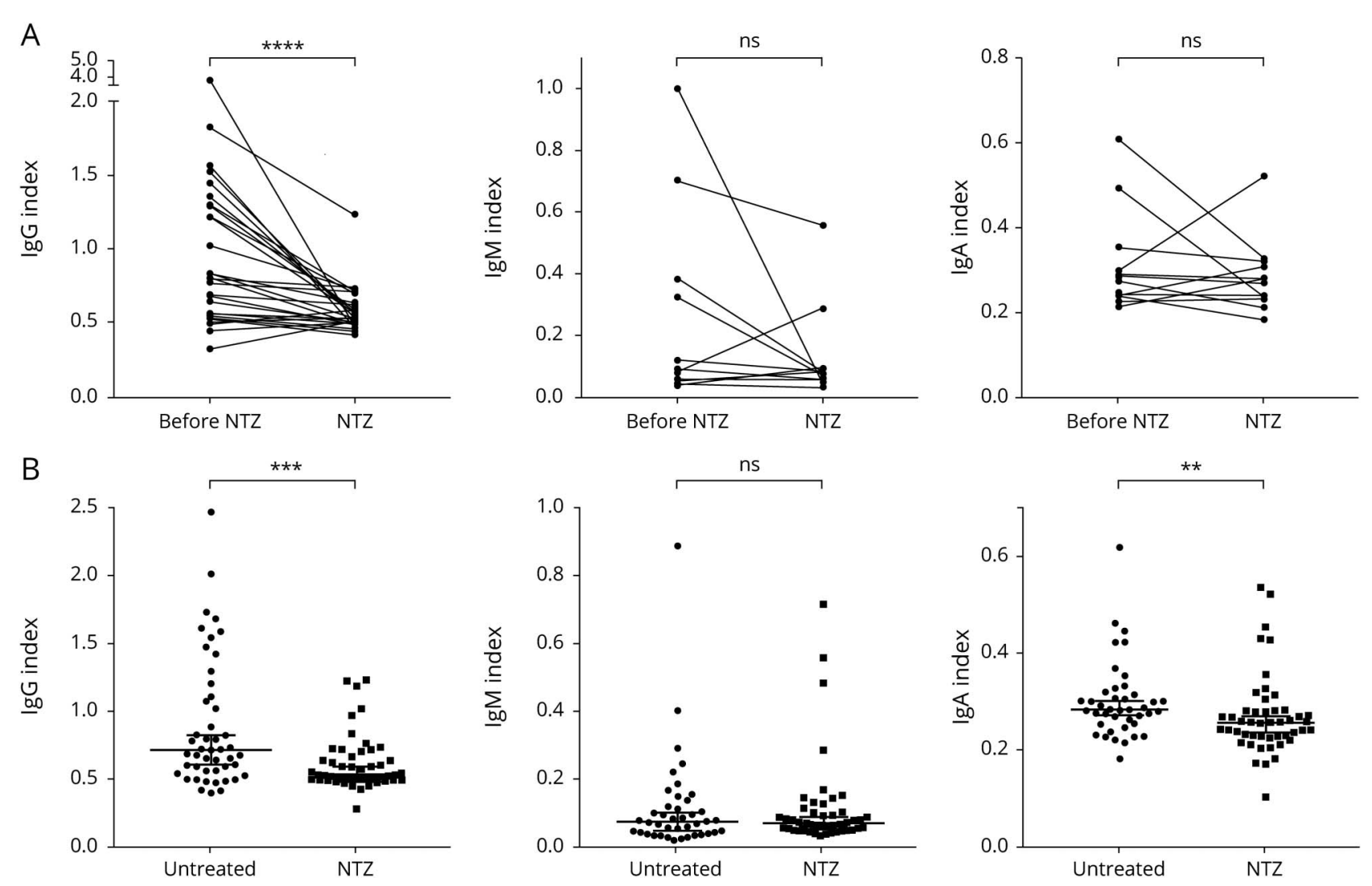

The Ig indices as a measure of intrathecal Ig production were calculated as described under Methods. Ig indices for IgG (left), IgM (middle), and IgA (right) are shown. (A) Longitudinal analysis: Paired data on Ig indices of patients before and during NTZ therapy were available for 26 patients for IgG, 13 patients for IgM, and 12 patients for IgA. IgG index (mean 1.0 before vs 0.6 during NTZ) was significantly reduced during NTZ therapy $(p<0.0001)$. Four patients with high IgM indices before NTZ showed a stronger reduction of IgM indices during NTZ treatment, but when the whole group was considered, the decrease in IgM indices (mean 0.2 before vs 0.1 during NTZ) did not reach statistical significance $(p=0.3054)$. IgA indices (mean before 0.3 vs 0.3 during NTZ) remained stable $(p=$ 0.4697). Wilcoxon matched-pairs signed-rank test. (B) Cross-sectional analysis: Each dot represents 1 patient. Patient numbers: IgG index: untreated $n=47$, NTZ $n=49$; IgM index: untreated $n=41, N T Z n=47 ;$ IgA index untreated $n=41, N T Z=47$. IgG and, to a lesser extent, IgA indices were lower in NTZ-treated compared with untreated MS patients $(p=0.0007$ and $p=0.0076)$. Mann-Whitney $U$ test. ns $=$ non significant; NTZ $=$ natalizumab. $* * p<0.01, * \star * p<0.001$, and $* \star * \star * p<0.0001$

163-16) approved the study. All patients and controls gave written informed consent.

\section{Results}

\section{Patient Characteristics}

The mean time of NTZ treatment duration in group 1 was 5.1 years. Patients had been on a mean of 2 DMT before starting NTZ. Most $(n=31)$ had been treated with basic DMT (interferon beta, glatiramer acetate, dimethyl fumarate, and teriflunomide) before starting NTZ, 10 patients with fingolimod, and 6 with other immunotherapies. Two patients were untreated before commencing NTZ treatment. None of the patients underwent cell-depleting MS therapies before NTZ. Clinical characteristics of all patients are shown in table 1 .

Results of routine CSF parameters (cell count, total protein, and blood-brain barrier dysfunction) of both groups before and after NTZ can be seen in table e-1 links.lww.com/NXI/A500.

\section{Isotype-Specific Effect of NTZ on Systemic and Intrathecal Ig Production}

NTZ strongly reduced the IgG index reflecting total intrathecal IgG production but had no effect on the IgM index as seen in both the cross-sectional and longitudinal part of our study (figure 1A, B). We noted a reduction of the IgA index in the cross-sectional study (figure 1B). In serum, NTZ therapy reduced IgM levels in both the longitudinal and crosssectional comparison; furthermore, we noted a slight reduction of IgG in only the longitudinal part of the study. IgA levels remained unchanged (figure e-1 links.lww.com/NXI/ A501). The reduction in serum IgM was substantial, from a mean of 1,307 to $653 \mathrm{mg} / \mathrm{L}$ ( $50 \%$ reduction) after a mean of 3.7 years of NTZ treatment. In 3 patients, the serum IgM level decreased below the reference value during NTZ treatment (figure e-1 links.lww.com/NXI/A501). IgG reduction was much less pronounced with a mean of $10.9 \mathrm{~g} / \mathrm{L}$ before and 9.8 $\mathrm{g} / \mathrm{L}$ during NTZ treatment (10\% reduction, 4.7 years of treatment). In the cross-sectional part of the study, 13 patients $(28 \%)$ in the NTZ group showed serum IgM levels below the 

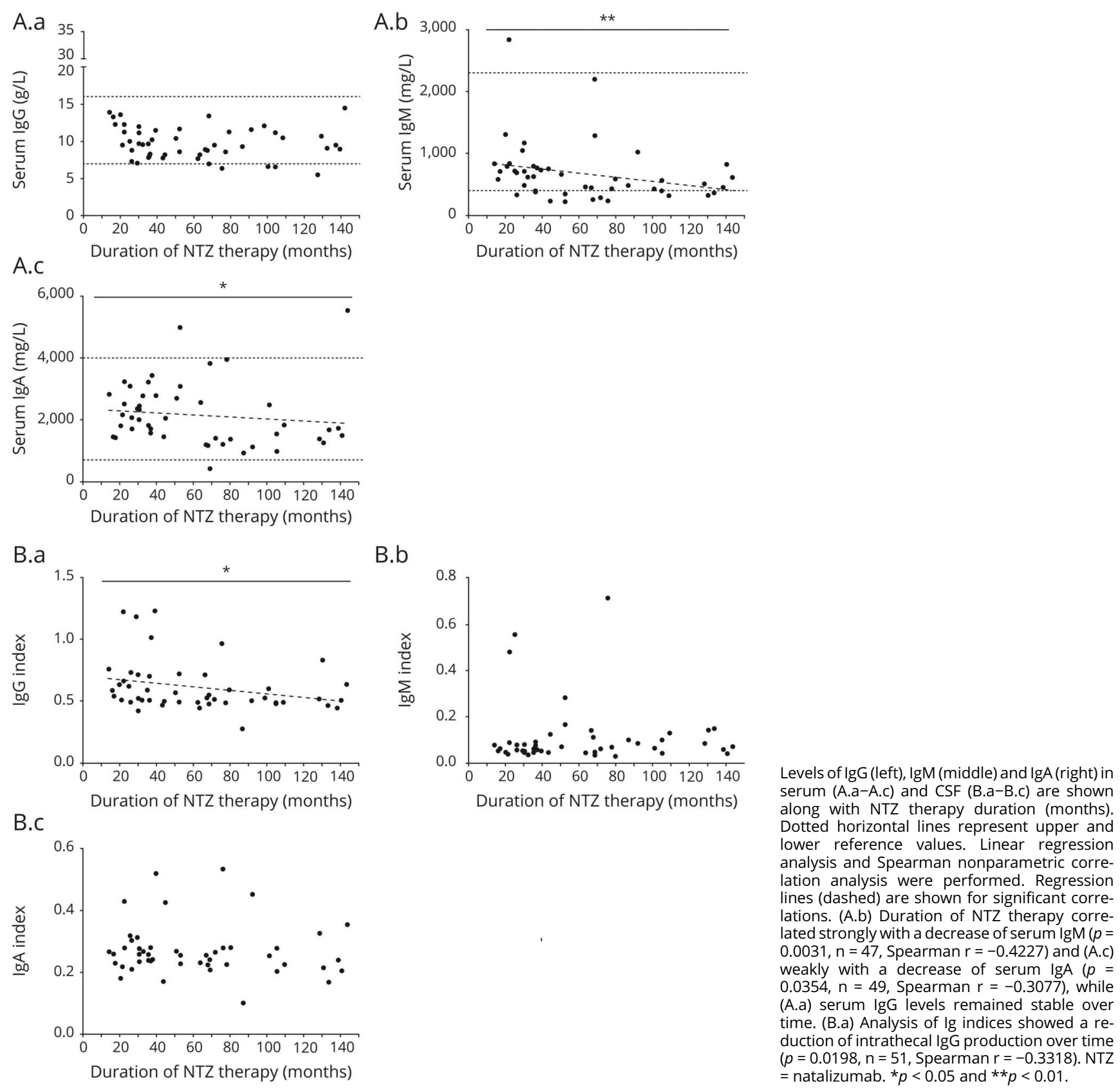

reference value compared with only 2 patients $(5 \%)$ in the untreated group ( $p=0.0048$, Fisher exact test). We further analyzed the effect of duration of NTZ application. In the CSF, we found a significant negative correlation between the duration of NTZ therapy and IgG index; in serum, IgA and IgM levels also decreased significantly with therapy duration (figure 2A, B). We observed a stronger decrease of IgM indices in the 4 patients with the highest IgM indices, but overall IgM indices in the CSF did not decline significantly after NTZ treatment (figure 1A). The total amount of IgM in the CSF declined significantly ( $p=0.0012$, data not shown). This indicates that reduced overall IgM in the CSF is due to reduced intrathecal IgM production in a few patients with a high IgM index and due to reduction of IgM in the serum. Taken together, NTZ strongly reduced systemic IgM levels and intrathecal IgG production.

\section{OCB Status and Individual OCBs Remain During NTZ Therapy}

The cross-sectional part of our study revealed no significant differences in $\mathrm{OCB}$ status between the untreated $(\mathrm{OCB}$ positive: $41 / 47,87 \%$ ) and NTZ-treated cohort (OCB positive: $37 / 49,76 \%$; figure $3 \mathrm{~A})$. A comparison of OCB in patients with MS before NTZ (OCB positive: $28 / 33,85 \%$ ) and 


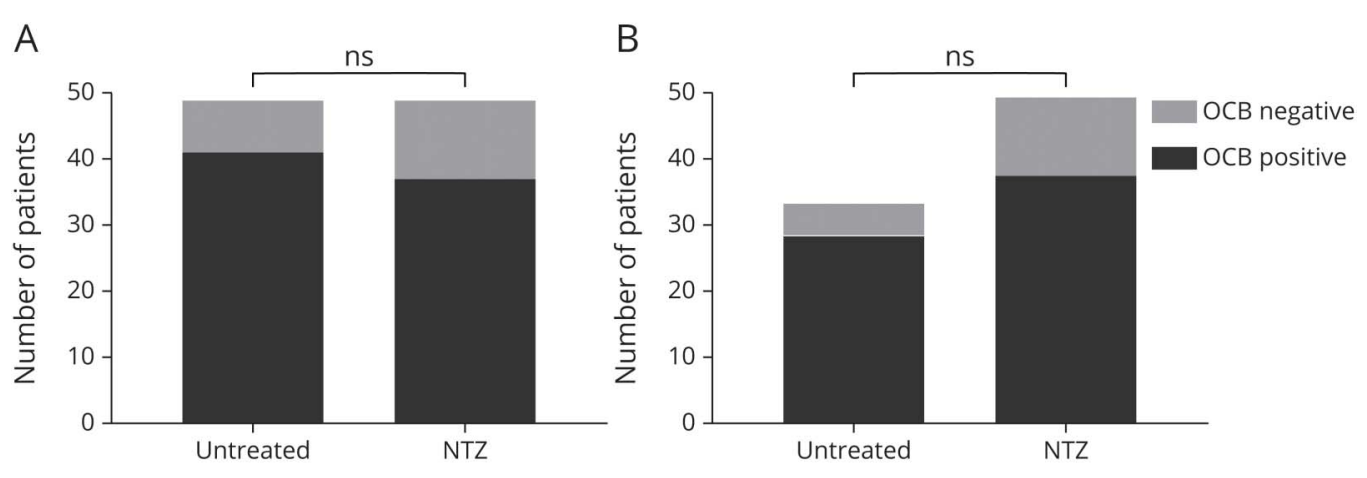

C

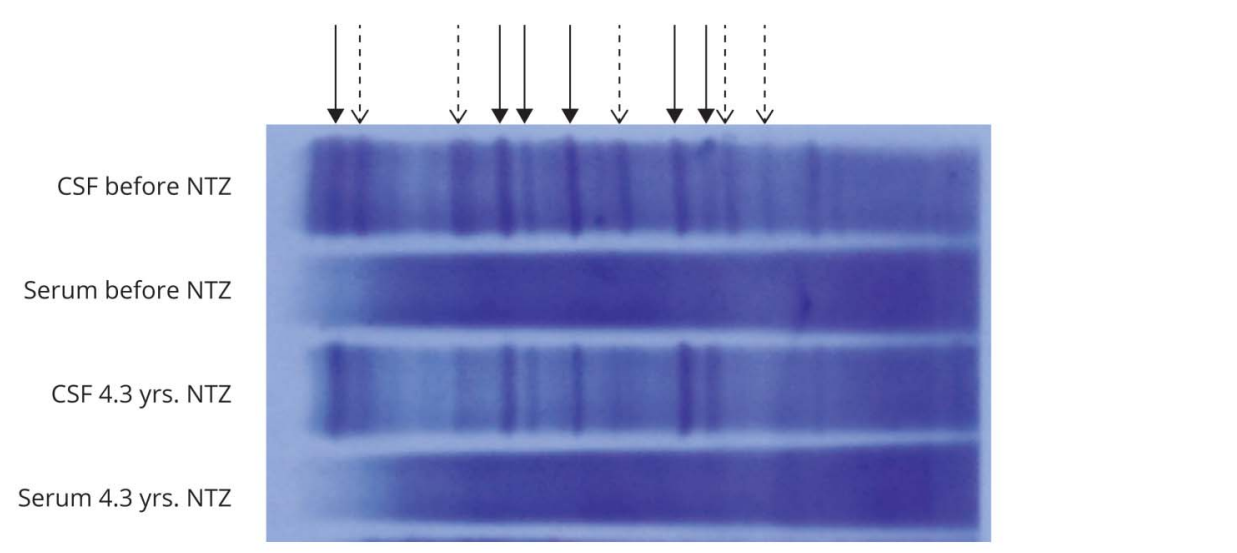

\section{D.a MRZ-1}

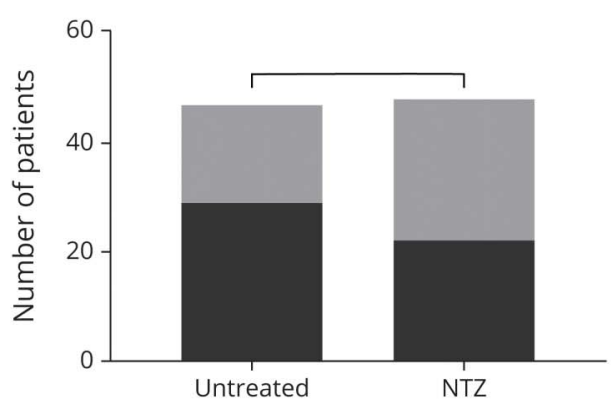

D.b MRZ-2

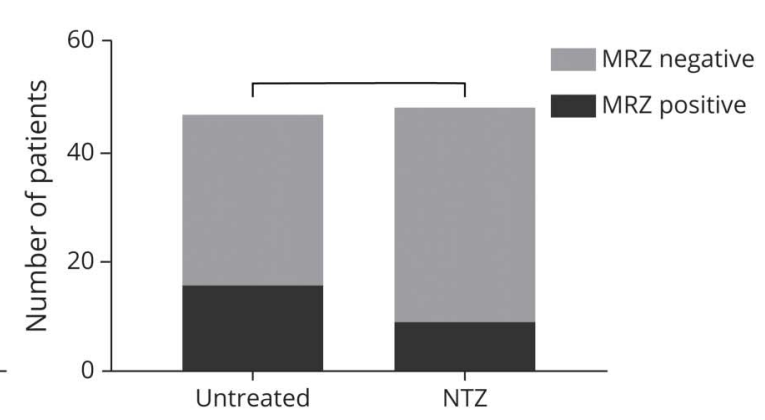

(A) Cross-sectional analysis of CSF-specific OCB: No differences in OCB status could be detected between untreated and NTZ-treated MS patients ( $p=0.1923$, untreated patients $n=47$, NTZ-treated patients $n=49$; OCB positive: $87 \%$ [n $=41$ ] of untreated patients vs $76 \%$ of NTZ patients [n=37]). Fisher exact test. (B) Longitudinal analysis of CSF-specific OCB: OCB status was similar in patients before and during NTZ treatment $(p=0.4082$, patients before NTZ $\mathrm{n}=33$, patients during NTZ $n=49$; OCB positive: $86 \%$ of patients before [ 28 patients] vs $76 \%$ of patients during NTZ [ $n=37$ ]). Fisher exact test. (C) Comparison of serum-CSF pairs of 1 patient with MS before NTZ therapy and after 4.3 years of NTZ treatment. The majority of bands persist during treatment (solid arrows), whereas some become weaker or disappear entirely (dashed arrows). (D) Cross-sectional analysis: MRZ reaction status of untreated and NTZ-treated patients. Positive MRZ reaction was defined as an intrathecal antibody reaction against 1 (D.a, MRZ-1) or 2 (D.b, MRZ-2) viruses (measles, rubella, or varicella zoster virus). No clear differences could be detected between untreated and NTZ-treated patients for MRZ-1 ( $p=0.1513$, MRZ-1 positive: $61 \%$ and $46 \%$, respectively) or MRZ-2 $(p=0.1069$, MRZ-2 positive: $34 \%$ and $19 \%$, respectively). Fisher exact test. MRZ = measles virus, rubella virus, and varicella zoster virus; ns = non significant; $\mathrm{NTZ}=$ natalizumab; $\mathrm{OCB}=$ oligoclonal band .

during NTZ treatment (OCB positive: 37/49, 76\%) also revealed similar proportions of OCB-positive patients (figure 3B). Overall, only 5 patients (18\%) lost their OCB during NTZ therapy. Taken together, long-term NTZ treatment does not have an effect on OCB status in most individuals.

To analyze the persistence or disappearance of individual OCB, we analyzed CSF/serum pairs of 1 patient, stored before the beginning of NTZ therapy and obtained after 4.3 years of treatment, in parallel on the same gel. This revealed the persistence of individual OCB. However, some of the OCB lost intensity or disappeared entirely (figure 3C).

\section{MRZ Reaction Status Remains Largely Unchanged During NTZ Treatment}

MRZ-1 reaction status was similar between untreated (MRZ1 positive: $29 / 47,62 \%)$ and NTZ-treated patients $(22 / 48$, $46 \%)$. Likewise, 16 of 47 (34\%) untreated MS patients were 


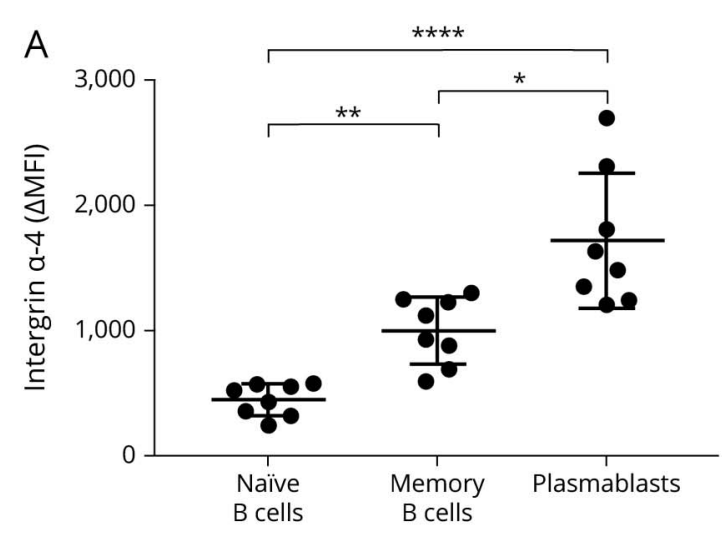

Isotype control

Interin a-4 stained sample

B.a Naïve B cells CD19+ CD38- CD27-

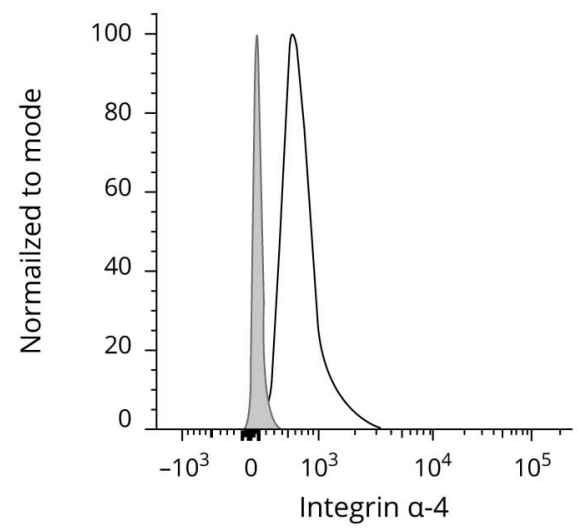

B.b Memory B cells CD19+CD38- CD27+

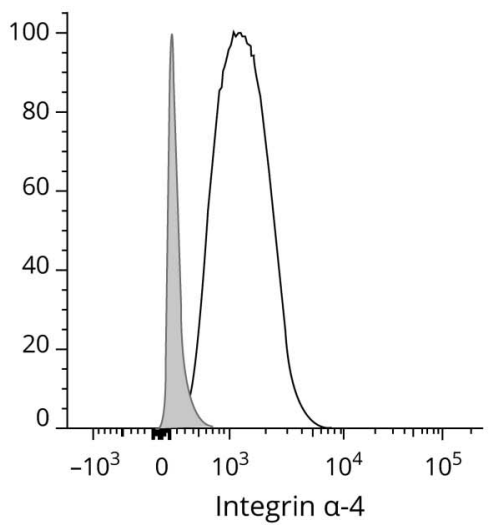

B.C Plasmablasts CD19+CD38+ CD27+

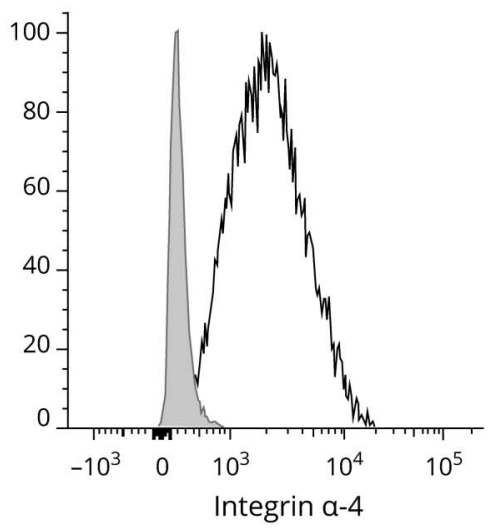

PBMCs of healthy donors $(n=8)$ were stained for a4-integrin (CD49d) and markers for flow cytometric differentiation of lymphocyte subsets. a4-Integrin

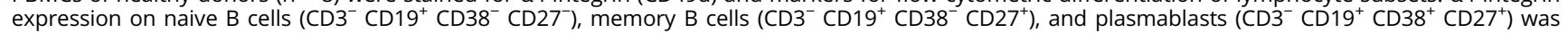
analyzed. (A) Each dot represents $\triangle \mathrm{MFI}$ (MFI[stained sample] - MFI[FMO control]) of 1 donor. a4-Integrin expression levels of memory cells and plasmablasts were significantly higher than those of naive B cells ( $p=0.0071$ and $p<0.00001$, respectively). a4-Integrin expression was higher on plasmablasts than on memory B cells $(p=0.0176)$. Quade all-pairs test. (B) Representative a4-integrin staining of 1 donor. Light gray curves represent isotype controls, and black curves represent a4-integrin staining on naive B cells (B.a), memory B cells (B.b), and plasmablasts (B.C). MFI = mean fluorescence intensity. ${ }^{*} p<0.05, * \star p<$ 0.01 , and $* * * * p<0.0001$.

MRZ-2 positive compared with 9 of 48 (19\%) NTZ-treated patients (figure 3D). NTZ treatment does not appear to affect the intrathecal $\mathrm{IgG}$ response to MRZ.

\section{Highest a4-Integrin Expression on Plasmablasts}

Analysis of a4-integrin expression on B-cell subsets in the blood of $\mathrm{HCs}$ revealed a different intensity level of $\alpha 4$-integrin expression on various B-cell subsets (figure 4). We observed the highest levels of a4-integrin on plasmablasts (CD19 ${ }^{+}$ $\left.\mathrm{CD} 38^{+} \mathrm{CD} 27^{+}\right)$, followed by memory B cells (CD $19^{+} \mathrm{CD} 38^{-}$ $\left.\mathrm{CD} 27^{+}\right)$and naive $\mathrm{B}$ cells $\left(\mathrm{CD} 19^{+} \mathrm{CD} 38^{-} \mathrm{CD} 27^{-}\right)$.

\section{Discussion}

Details of the intrathecal Ig production in MS are useful for distinguishing MS from other neuroinflammatory diseases ${ }^{1,4}$ and are of prognostic relevance: intrathecal IgM production is linked to conversion of clinically isolated syndrome to $\mathrm{MS}^{21}$ and correlates with disease activity ${ }^{22}$; in addition, intrathecal IgG production is associated with worsening. ${ }^{23}$ Here, we present a comprehensive analysis of the effects of long-term NTZ therapy on different features of intrathecal Ig production and show that $\alpha 4$-integrin is expressed more highly on plasmablasts than on naive and memory B cells. NTZ reduced total intrathecal IgG production, correlating with treatment duration, but the intrathecal polyspecific IgG response (MRZ reaction) and OCB (consisting of IgG) remained. This was seen in both the longitudinal and the cross-sectional part of our analysis. Moreover, we found that individual OCBs persisted in a patient despite 4.3 years of NTZ treatment.

In the MS brain, Ig-producing cells are found in parenchymal, perivascular, and meningeal areas ${ }^{7,24}$ as well as in the spinal fluid. ${ }^{1,8,25}$ Both short-lived plasmablasts ${ }^{8}$ and long-lived plasma cells ${ }^{7}$ are considered to contribute to intrathecal Ig production in MS. In patients with MS, OCBs in the CSF remain stable for many years, ${ }^{26}$ indicating that individual long-lived plasma cells migrate to a survival niche in the CNS and remain there. ${ }^{5}$ The 
presence of OCB after a shorter period of NTZ treatment than in this study has been analyzed before with mixed results. ${ }^{15,17-19}$ A more recent study revealed the persistence of OCB in more than $90 \%$ of patients with MS after 1 year of NTZ therapy. ${ }^{15}$ Both the longitudinal and cross-sectional part of our study showed that the OCB status remained largely unchanged even after long-term NTZ therapy. We could further directly compare individual OCB in CSF samples obtained before and more than 4 years after NTZ treatment on the same gel. This revealed that not only OCB status but also individual bands remained, indicating that NTZ did not remove the corresponding plasma cells from their niche. We also noted that a few bands became weaker or disappeared. It is unclear whether this is due to NTZ or reflects a natural disease process because changes in OCB banding patterns have been described in some patients with MS. ${ }^{27,28}$

A limitation of this study is the relatively long time span between the first LP and the beginning of NTZ therapy; hence, effects of other disease-modifying drugs before NTZ or even disease course itself on the development of the analyzed parameters over time cannot be entirely excluded. Furthermore, we were only able to analyze the persistence of individual OCBs after long-term treatment in 1 individual patient.

Intrathecal IgG production in patients with MS often involves a polyspecific response against different pathogens (MRZ reaction), which in some countries is used to support the diagnosis. MRZ reaction is typically present at the beginning of the disease and relatively specific for MS, whereas OCB can also be detected in other entities of CNS inflammation, e.g., neuroborreliosis. ${ }^{4}$ Quantitatively, the MRZ reaction represents only a minor part of intrathecally produced IgG, estimated around $2 \%{ }^{3}$ The MRZ reaction may indicate an enhanced B-cellpromoting environment long before the onset of clinical disease and may also reflect the individual's history of infections. ${ }^{5}$ In the absence of treatment, MRZ reaction persists, ${ }^{5}$ presumably reflecting-like persisting $\mathrm{OCB}$ - that long-lived plasma cells have found a survival niche in the brain. In our study, the MRZ reaction was not abrogated by 5.1 years of treatment with NTZ. A previous study reported the persistence of MRZ reaction after 1 year of NTZ therapy but differential effects on other antiviral IgG responses. ${ }^{13}$ It is tempting to speculate that this is due to a differential formation of long-lived plasma cells by these different antiviral responses. Both the persisting OCB and the persisting MRZ reaction indicate that $a 4$-integrin is not a major component of the survival niche of plasma cells in the CNS. In the bone marrow, laminin $\beta 1$ has been identified as an important adhesion molecule for IgG-secreting plasma cells. ${ }^{29}$ The role of laminin $\beta 1$ in maintenance of plasma cells in the CNS remains to be identified.

The magnitude of intrathecal IgG production was reported to correlate with the number of short-lived plasmablasts in the $\mathrm{CSF}^{8}{ }^{8} \mathrm{We}$ assume that the reduction of intrathecal IgG production by NTZ is based on its effect on plasmablasts and comprises 2 mechanisms: First, NTZ might reduce the new formation of plasmablasts because B-cell activation is facilitated by VLA- 4 (integrin $\alpha 4 \beta 1$ ) interacting with VCAM- $1 .{ }^{30}$ Second, NTZ could reduce homing of plasmablasts to the CNS. Plasmablasts are circulating cells, ${ }^{31}$ and B cells exchange between the CNS and peripheral compartment. ${ }^{10}$ Our finding of a high expression of integrin $a 4$ on plasmablasts suggests that NTZ also reduces the migration of plasmablasts to the CNS. Animal models underscore the importance of integrin a4-dependent migration of B cells for disease development and show different effects depending on the particular model. ${ }^{32-35}$

In serum, we found that NTZ strongly reduced IgM, with little or no effect on IgG and IgA levels, in accordance with previous reports. ${ }^{12,15}$ This differential effect of NTZ on systemic IgG and IgM levels can also be explained by an inhibition of plasmablasts but not long-lived plasma cells. Serum IgG levels are largely maintained by long-lived plasma cells, ${ }^{6}$ whereas IgM is produced to a greater extent by short-lived plasmablasts, although also long-lived IgM plasma cells have been described. ${ }^{36}$ These may contribute to IgM remaining in the presence of NTZ. ${ }^{30}$ Whether patients who switch from NTZ to B-celldepleting therapies might subsequently develop earlier and more pronounced hypogammaglobulinemias has not been investigated in detail. Although this has to be evaluated in larger studies, we would recommend determination of serum immunoglobulin levels in patients with infections during NTZ therapy and close monitoring in patients before and after switching to cell-depleting therapies.

In summary, we show that long-term treatment with NTZ has differential effects on features of intrathecal IgG production: NTZ time dependently reduces the intrathecal IgG index and serum IgM levels, but OCB status, MRZ reaction, and individual OCB remain largely unchanged. This indicates that NTZ targets short-lived plasmablasts, but not long-lived plasma cells in their survival niche in the brain.

\section{Acknowledgment}

The authors are grateful to Sabine Lüngen, Angelika Bamberger, and Martina Sölch for their support and Dr. Hannah Pellkofer for comments on the manuscript. The authors thank Dr. Stephan Endres, Department of Medical Technology and IT, LMU Klinikum, Munich, for providing integrated structured patient data for analysis and Dr. Markus Krumbholz, Department of Neurology, Eberhard Karls University, Tübingen, for his valuable support. The authors acknowledge the Core Facility Flow Cytometry at the Biomedical Center, Ludwig-MaximiliansUniversität München, for providing equipment and expertise.

\section{Study Funding \\ DFG (SFB TR128).}

\section{Disclosure}

M. Schlüter, E. Oswald, and S. Winklmeier report no disclosures relevant to the manuscript. I. Meinl received travel 
expenses from MedDay and Roche Pharma and compensation from Serono and Roche Pharma. J. Havla reports grants for OCT research from the Friedrich-Baur-Stiftung and Merck; personal fees and nonfinancial support from Celgene, Merck, Alexion, Novartis, Roche, Santhera, Biogen, Heidelberg Engineering, and Sanofi Genzyme; and nonfinancial support of the Guthy-Jackson Charitable Foundation, all outside the submitted work. J. Havla is partially funded by the German Federal Ministry of Education and Research (DIFUTURE) (grant nos. 01ZZ1603[A-D] and 01ZZ1804[A-H]). P. Eichhorn reports no disclosures relevant to the manuscript. E. Meinl received honorarium from Roche, Novartis, Merck, Sanofi, Biogen, and Bioeq and grant support from Novartis, Sanofi, Roche, and Merck. T. Kümpfel received speaker honoraria/personal compensation from Bayer HealthCare, Merck, Novartis Pharma, Roche Pharma, and Biogen as well as grant support from Novartis; advisory board for Roche Pharma. Go to Neurology.org/NN for full disclosures.

\section{Publication History}

Received by Neurology: Neuroimmunology \& Neuroinflammation December 11, 2020. Accepted in final form April 16, 2021.

\section{Appendix Authors}

\begin{tabular}{|c|c|c|}
\hline Name & Location & Contribution \\
\hline $\begin{array}{l}\text { Miriam } \\
\text { Schlüter, MD }\end{array}$ & $\begin{array}{l}\text { Institute of Clinical } \\
\text { Neuroimmunology, } \\
\text { Biomedical Center and } \\
\text { LMU Klinikum, Munich, } \\
\text { Germany }\end{array}$ & $\begin{array}{l}\text { Drafting/revision of the } \\
\text { manuscript for content, } \\
\text { including medical writing for } \\
\text { content; major role in the } \\
\text { acquisition of data; and analysis } \\
\text { or interpretation of data }\end{array}$ \\
\hline $\begin{array}{l}\text { Eva Oswald, } \\
\text { BSc }\end{array}$ & $\begin{array}{l}\text { Institute of Clinical } \\
\text { Neuroimmunology, } \\
\text { Biomedical Center and } \\
\text { LMU Klinikum, Munich, } \\
\text { Germany }\end{array}$ & $\begin{array}{l}\text { Major role in the acquisition of } \\
\text { data and analysis or } \\
\text { interpretation of data }\end{array}$ \\
\hline $\begin{array}{l}\text { Stephan } \\
\text { WinkImeier, } \\
\text { MSc }\end{array}$ & $\begin{array}{l}\text { Institute of Clinical } \\
\text { Neuroimmunology, } \\
\text { Biomedical Center and } \\
\text { LMU Klinikum, Munich, } \\
\text { Germany }\end{array}$ & $\begin{array}{l}\text { Major role in the acquisition of } \\
\text { data }\end{array}$ \\
\hline $\begin{array}{l}\text { Ingrid Meinl, } \\
\text { MD }\end{array}$ & $\begin{array}{l}\text { Institute of Clinical } \\
\text { Neuroimmunology, } \\
\text { Biomedical Center and } \\
\text { LMU Klinikum, Munich, } \\
\text { Germany }\end{array}$ & $\begin{array}{l}\text { Major role in the acquisition of } \\
\text { data }\end{array}$ \\
\hline $\begin{array}{l}\text { Joachim } \\
\text { Havla, MD }\end{array}$ & $\begin{array}{l}\text { Institute of Clinical } \\
\text { Neuroimmunology, } \\
\text { Biomedical Center and } \\
\text { LMU Klinikum, Munich, } \\
\text { Germany }\end{array}$ & $\begin{array}{l}\text { Major role in the acquisition of } \\
\text { data }\end{array}$ \\
\hline $\begin{array}{l}\text { Peter } \\
\text { Eichhorn, } \\
\text { MD }\end{array}$ & $\begin{array}{l}\text { Institute of Laboratory } \\
\text { Medicine, LMU Klinikum, } \\
\text { Munich, Germany }\end{array}$ & $\begin{array}{l}\text { Major role in the acquisition of } \\
\text { data }\end{array}$ \\
\hline $\begin{array}{l}\text { Edgar Meinl, } \\
\text { MD }\end{array}$ & $\begin{array}{l}\text { Institute of Clinical } \\
\text { Neuroimmunology, } \\
\text { Biomedical Center and } \\
\text { LMU Klinikum, Munich, } \\
\text { Germany }\end{array}$ & $\begin{array}{l}\text { Drafting/revision of the } \\
\text { manuscript for content, } \\
\text { including medical writing for } \\
\text { content; study concept or } \\
\text { design; and analysis or } \\
\text { interpretation of data }\end{array}$ \\
\hline
\end{tabular}

Appendix (continued)

\begin{tabular}{lll}
\hline Name & Location & Contribution \\
\hline $\begin{array}{l}\text { Tania } \\
\text { Kümpfel, }\end{array}$ & Institute of Clinical & Neuroimmunology, \\
MD & $\begin{array}{l}\text { Biomedical Center and } \\
\text { manuscript for content, } \\
\text { LMU Klinikum, Munich, } \\
\text { including medical writing for } \\
\text { Germany }\end{array}$ & $\begin{array}{l}\text { content; study concept or } \\
\text { design; and analysis or } \\
\text { interpretation of data }\end{array}$ \\
\hline
\end{tabular}

\section{References}

1. Stangel M, Fredrikson S, Meinl E, Petzold A, Stüve O, Tumani H. The utility of cerebrospinal fluid analysis in patients with multiple sclerosis. Nat Rev Neurol. 2013; 9(5):267-276

2. Milstein JL, Barbour CR, Jackson K, Kosa P, Bielekova B. Intrathecal, not systemic inflammation is correlated with multiple sclerosis severity, especially in progressive multiple sclerosis. Front Neurol. 2019;10:1232.

3. Reiber $\mathrm{H}$, Ungefehr S, Jacobi C. The intrathecal, polyspecific and oligoclonal immune response in multiple sclerosis. Mult Scler. 1998;4(3):111-117.

4. Jarius S, Eichhorn P, Franciotta D, et al. The MRZ reaction as a highly specific marker of multiple sclerosis: re-evaluation and structured review of the literature. J Neurol. 2017;264(3):453-466.

5. Meinl E, Krumbholz M, Hohlfeld R. B lineage cells in the inflammatory central nervous system environment: migration, maintenance, local antibody production, and therapeutic modulation. Ann Neurol. 2006;59(6):880-892.

6. Manz RA, Hauser AE, Hiepe F, Radbruch A. Maintenance of serum antibody levels. Annu Rev Immunol. 2005;23:367-386.

7. Pollok K, Mothes R, Ulbricht C, et al. The chronically inflamed central nervous system provides niches for long-lived plasma cells. Acta Neuropathol Commun. 2017;5(1):88.

8. Cepok S, Rosche B, Grummel V, et al. Short-lived plasma blasts are the main B cell effector subset during the course of multiple sclerosis. Brain. 2005;128:1667-1676.

9. Gasperi C, Andlauer TFM, Keating A, et al. Genetic determinants of the humoral immune response in MS. Neurol Neuroimmunol Neuroinflamm. 2020;7(5):e827.

10. von Budingen HC, Kuo TC, Sirota M, et al. B cell exchange across the blood-brain barrier in multiple sclerosis. J Clin Invest. 2012;122(12):4533-4543.

11. Krumbholz M, Meinl I, Kümpfel T, Hohlfeld R, Meinl E. Natalizumab disproportionately increases circulating pre-B and B cells in multiple sclerosis. Neurology. 2008; 71(17):1350-1354.

12. Selter RC, Biberacher V, Grummel V, et al. Natalizumab treatment decreases serum IgM and IgG levels in multiple sclerosis patients. Mult Scler. 2013;19(11):1454-1461.

13. Planas R, Jelčić I, Schippling S, Martin R, Sospedra M. Natalizumab treatment perturbs memory- and marginal zone-like B-cell homing in secondary lymphoid organs in multiple sclerosis. Eur J Immunol. 2012;42(3):790-798.

14. Niino M, Bodner C, Simard ML, et al. Natalizumab effects on immune cell responses in multiple sclerosis. Ann Neurol. 2006;59(5):748-754.

15. Largey F, Jelcic I, Sospedra M, Heesen C, Martin R, Jelcic I. Effects of natalizumab therapy on intrathecal antiviral antibody responses in MS. Neurol Neuroimmunol Neuroinflamm. 2019;6(6):e621.

16. Stüve $\mathrm{O}$, Marra $\mathrm{CM}$, Jerome $\mathrm{KR}$, et al. Immune surveillance in multiple sclerosis patients treated with natalizumab. Ann Neurol. 2006;59(5):743-747.

17. Warnke C, Stettner M, Lehmensiek V, et al. Natalizumab exerts a suppressive effect on surrogates of B cell function in blood and CSF. Mult Scler. 2015;21(8):1036-1044.

18. Harrer A, Tumani H, Niendorf S, et al. Cerebrospinal fluid parameters of B cell-related activity in patients with active disease during natalizumab therapy. Mult Scler. 2013; 19(9):1209-1212.

19. Mancuso R, Franciotta D, Rovaris M, et al. Effects of natalizumab on oligoclonal bands in the cerebrospinal fluid of multiple sclerosis patients: a longitudinal study. Mult Scler. 2014;20(14):1900-1903.

20. Reiber H, Lange P. Virus-spezifische Antikörper in Liquor und Serum. ELISAAnalytik und Auswertung mittels Antikörper-Index und Quotientendiagramm. Lab Med. 1991;15:204-207.

21. Pfuhl C, Grittner U, Gieß RM, et al. Intrathecal IgM production is a strong risk factor for early conversion to multiple sclerosis. Neurology. 2019;93(15):e1439-e1451.

22. Magliozzi R, Mazziotti V, Montibeller L, et al. Cerebrospinal fluid IgM levels in association with inflammatory pathways in multiple sclerosis patients. Front Cell Neurosci. 2020;14(338):569827.

23. Gasperi C, Salmen A, Antony G, et al. Association of intrathecal immunoglobulin G synthesis with disability worsening in multiple sclerosis. JAMA Neurol. 2019;76(7):841-849.

24. Magliozzi R, Howell O, Vora A, et al. Meningeal B-cell follicles in secondary progressive multiple sclerosis associate with early onset of disease and severe cortical pathology. Brain. 2007;130(pt 4):1089-1104.

25. Obermeier B, Mentele R, Malotka J, et al. Matching of oligoclonal immunoglobulin transcriptomes and proteomes of cerebrospinal fluid in multiple sclerosis. Nat Med. $2008 ; 14(6): 688-693$.

26. Walsh MJ, Tourtellotte WW. Temporal invariance and clonal uniformity of brain and cerebrospinal IgG, IgA, and IgM in multiple sclerosis. J Exp Med. 1986;163(1). 41-53. 
27. Thompson EJ, Kaufmann P, Rudge P. Sequential changes in oligoclonal patterns during the course of multiple sclerosis. J Neurol Neurosurg Psychiatry. 1983;46(6):547-550.

28. Axelsson M, Mattsson N, Malmeström C, Zetterberg H, Lycke J. The influence of disease duration, clinical course, and immunosuppressive therapy on the synthesis of intrathecal oligoclonal IgG bands in multiple sclerosis. J Neuroimmunol. 2013;264(1-2):100-105.

29. Männe C, Takaya A, Yamasaki Y, et al. Salmonella SiiE prevents an efficient humoral immune memory by interfering with $\operatorname{IgG}(+)$ plasma cell persistence in the bone marrow. Proc Natl Acad Sci U S A. 2019;116(15):7425-7430.

30. Carrasco YR, Batista FD. B-cell activation by membrane-bound antigens is facilitated by the interaction of VLA-4 with VCAM-1. EMBO J. 2006;25(4):889-899.

31. Odendahl M, Mei H, Hoyer BF, et al. Generation of migratory antigen-specific plasma blasts and mobilization of resident plasma cells in a secondary immune response. Blood. 2005;105(4):1614-1621.
32. Lehmann-Horn K, Sagan SA, Bernard CC, Sobel RA, Zamvil SS. B-cell very late antigen-4 deficiency reduces leukocyte recruitment and susceptibility to central nervous system autoimmunity. Ann Neurol. 2015;77(5):902-908.

33. Lehmann-Horn K, Sagan SA, Winger RC, et al. CNS accumulation of regulatory B cells is VLA-4-dependent. Neurol Neuroimmunol Neuroinflamm. 2016;3(2):e212.

34. Glatigny $S$, Wagner CA, Bettelli E. Cutting edge: integrin $a 4$ is required for regulatory B cell control of experimental autoimmune encephalomyelitis. I Immunol. 2016;196(9):3542-3546.

35. Hussain RZ, Cravens PD, Miller-Little WA, et al. a4-integrin deficiency in B cells does not affect disease in a T-cell-mediated EAE disease model. Neurol Neuroimmunol Neuroinflamm. 2019;6(4):e563.

36. Bohannon C, Powers R, Satyabhama L, et al. Long-lived antigen-induced IgM plasma cells demonstrate somatic mutations and contribute to long-term protection. Nat Commun. 2016;7:11826. 


\section{Neurology ${ }^{\oplus}$ \\ Neuroimmunology \& Neuroinflammation}

\section{Effects of Natalizumab Therapy on Intrathecal Immunoglobulin G Production Indicate}

Targeting of Plasmablasts

Miriam Schlüter, Eva Oswald, Stephan Winklmeier, et al.

Neurol Neuroimmunol Neuroinflamm 2021;8;

DOI 10.1212/NXI.0000000000001030

This information is current as of July 1, 2021

Neurol Neuroimmunol Neuroinflamm is an official journal of the American Academy of Neurology.

Published since April 2014, it is an open-access, online-only, continuous publication journal. Copyright

Copyright $\odot 2021$ The Author(s). Published by Wolters Kluwer Health, Inc. on behalf of the American

Academy of Neurology.. All rights reserved. Online ISSN: 2332-7812.

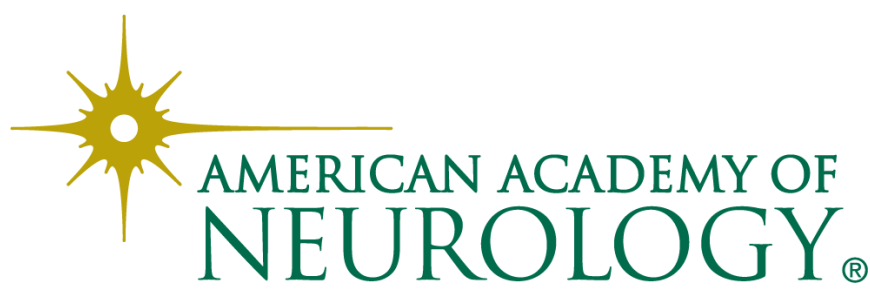




\section{Updated Information \& Services}

References

Subspecialty Collections

Permissions \& Licensing

\section{Reprints}

including high resolution figures, can be found at: http://nn.neurology.org/content/8/5/e1030.full.html

This article cites 36 articles, 10 of which you can access for free at: http://nn.neurology.org/content/8/5/e1030.full.html\#\#ref-list-1

This article, along with others on similar topics, appears in the following collection(s):

All Demyelinating disease (CNS)

http://nn.neurology.org//cgi/collection/all_demyelinating_disease_cns All Immunology

http://nn.neurology.org//cgi/collection/all_immunology

Autoimmune diseases

http://nn.neurology.org//cgi/collection/autoimmune_diseases

Cerebrospinal Fluid

http://nn.neurology.org//cgi/collection/cerebrospinal_fluid

Multiple sclerosis

http://nn.neurology.org//cgi/collection/multiple_sclerosis

Information about reproducing this article in parts (figures,tables) or in its entirety can be found online at:

http://nn.neurology.org/misc/about.xhtml\#permissions

Information about ordering reprints can be found online: http://nn.neurology.org/misc/addir.xhtml\#reprintsus

Neurol Neuroimmunol Neuroinflamm is an official journal of the American Academy of Neurology.

Published since April 2014, it is an open-access, online-only, continuous publication journal. Copyright

Copyright $\odot 2021$ The Author(s). Published by Wolters Kluwer Health, Inc. on behalf of the American Academy of Neurology.. All rights reserved. Online ISSN: 2332-7812.

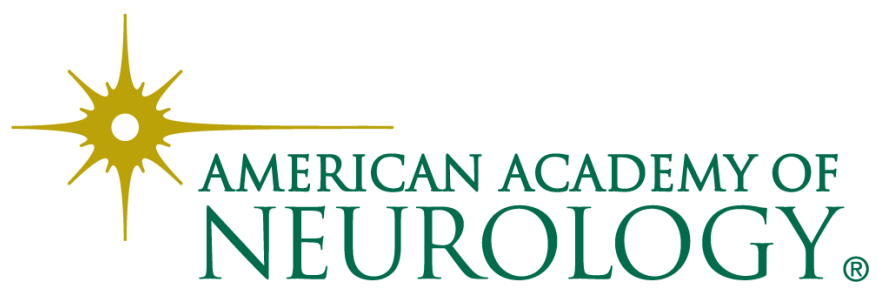

